\title{
Delineation of Bitumen Saturated Zones in Agbabu, Southwestern Nigeria, Using an Integrated Geophysical Methods
}

\author{
Alagbe Olufemi Adigun \\ Department of Applied Geophysics, Federal University of Technology, Akure, Nigeria \\ Email address: \\ oaalagbe@futa.edu.ng, alagbefemi@yahoo.co.uk

\section{To cite this article:} \\ Alagbe Olufemi Adigun. Delineation of Bitumen Saturated Zones in Agbabu, Southwestern Nigeria, Using an Integrated Geophysical \\ Methods. Journal of Energy and Natural Resources. Vol. 9, No. 3, 2020, pp. 88-97. doi: 10.11648/j.jenr.20200903.11
}

Received: June 13, 2020; Accepted: June 24, 2020; Published: July 13, 2020

\begin{abstract}
Delineation of bitumen saturated zones in Agbabu, southwestern Nigeria was carried out using an integrated geophysical methods involving the groundmagnetic and electrical resistivity methods. A total of four magnetic traverses were established in the East-west direction, each covering a total length of $130 \mathrm{~m}$. The groundmagnetic results revealed geologic structures favourable to accumulation of bitumen and its occurrence at near-surface. It was also revealed that the bituminous zone trend in the East- West direction of the study area. Two techniques was adopted under electrical resistivity method, the horizontal electrica profiling (HEP) and the vertical electrical sounding (VES). The HEP was used to measure the subsurface electrical variations and lateral extent of bitumen over the study area. Four traverses were established in the North-South direction for HEP and were used to generate electrical profiling curves, which showed low resistivity signatures over the study area. The low resistivity signatures were attributed to the intrusion of saline water to the bituminous zones. Two vertical electrical soundings (VES) were carried out, VES1 and VES2 which were carried out on traverse 1 and traverse 3 had five and six geologic layers respectively. The bitumen saturated zones were found to be within layers three and four and underlained by saline water. The average depth to the bitumen saturated zones was found to be between $3.1 \mathrm{~m}$ and $23.3 \mathrm{~m}$ downwards. The near-surface occurrence of natural bitumen and the intrusion of saline water might hinder the feasibility of pure and quality water from the shallow hand-dug wells within the study area.
\end{abstract}

Keywords: Agbabu, Bitumen, Saturated Zone, Horizontal Electrical Profiling, Faults, Groundmagnetic

\section{Introduction}

Bitumen is described as a viscous liquid, or a solid, consisting essentially of hydrocarbons and their derivatives, which is soluble in trichloroethylene and is substantially nonvolatile and softens gradually when heated. It is black or brown in colour and possesses waterproofing and adhesive properties. It is obtained by refinery processes from petroleum, and is also found as a natural deposit or as a component of naturally occurring asphalt, in which it is associated with mineral matter [1]. Oil sands, known as tar sands are composed of bitumen, mineral matter which includes clay or sand and water. Bitumen is also referred to as heavy oil and it constitutes an important energy resource. It is highly viscous oil with API $<20^{\circ} \mathrm{C}$ and it is regarded as the biogenic product of crude oil found in the sedimentary environment [2].
Bitumen can be found in some countries in American like U.S.A, Canada, Venezuela, Mexico and Brazil, it can also be found in some European countries such as U.K, Russia, Turkey, Italy, France, Spain and some Asia countries. Also in Africa, bitumen can be found in countries like Egypt, Algeria and Nigeria [1].

Bitumen is usually and majorly found in the sedimentary basin of Nigeria which is particularly in the darhomey basin, with Ondo State being the most noted area of bitumen activities in the belt and has offices of Nigerian Bitumen Development Project located at Akure and Ore. Generally, some distinct bitumen-impregnated hydrocarbon types of occurrence have been identified within the Nigerian bitumen belt from topsoil downwards and location to location as: Outcrop, rich sands, lean sands, shales and heavy crudes [3].

Nonetheless, large amounts of bitumen occur in 
concentrated (natural) form in nature. Naturally occurring deposits of bitumen are formed from the remains of ancient, microscopic algae (diatoms) and other once-living things. This natural bitumen is believed to be the remnants of very large volumes of conventional oils that have been generated and subsequently degraded, principally by bacterial action. These remains were deposited in the mud on the bottom of the ocean or lake where the organisms lived. Under the heat (above $50^{\circ} \mathrm{C}$ ) and pressure of burial deep in the Earth, the remains were transformed into materials such as asphalt/bitumen, kerogen, or petroleum [4].

Bitumen is a mixture of organic liquids that are highly viscous, black, sticky and entirely soluble in carbon disulphide. The elemental composition of bitumen includes 79-88\% Carbon, 7-13\% Hydrogen; trace to 3\% Nitrogen, $8 \%$ Sulphur, $8 \%$ Oxygen by weight. When the light fractions (paraffin) are lost through natural processes after evolution from organic source materials, the oil becomes heavy, with a high proportion of asphaltic molecules, and with substitution in the carbon network of heteroatoms such as nitrogen, sulfur, and oxygen. Therefore, heavy oil, regardless of source, always contains the heavy fractions (naphthene and aromatic). Most naturally occurring bitumen contains nickel and vanadium in less than 10ppm level. [5].

The largest deposits of bitumen in the world were reported to be found in Venezuela, Canada, and Saudi Arabia respectively. Studies also revealed that Nigeria has a reserve estimate of 30-40 billion barrels (bbls) bitumen with potential recovery of $3654 \times 10^{6}$ bbls [6].

The occurrence of bitumen in southwestern Nigeria has been recorded from boreholes and seepages [3].

The oil sand outcrops lie across the East-West belt, approximately $120 \mathrm{~km}$ long and $4-6 \mathrm{~km}$ wide, cutting across Edo, Ondo and Ogun states as seepages on farmlands, along road cuts and as surface and near surface impregnated sediments exposed along river banks and at break of slopes. Occurrence of the seepage and tar sand deposit over the Okitipupa ridge in the Dahomey basin provided the initial impetus for oil exploration in Nigeria [7, 8].

Natural bitumens consist mostly of hydrocarbons (paraffinic, naphthenic, and aromatic) but also include various amounts of nonhydrocarbon heterocyclic compounds, which incorporate nitrogen, oxygen, sulfur, and trace metals as substituents [9].

Bitumen was used in ancient times as far back as over 3,500 BC for corpse preservation such as the Egyptian mummifications of the Pharaohs. It was also used for water proofing of baskets. It is primarily used today for paving roads and parking lots, roofing, corrosion protection, general industrial and special purposes. Oxidized bitumen is used for pipe coating, manufacture of paints, hydraulic applications, under sealing for concrete pavement [10].

In Nigeria, natural bitumen has been found in Ondo, Lagos, Ogun, Edo, and Enugu States with a combined proven reserve of about 14.86 billion barrels. Very rich natural bitumen deposits are found in Ondo State around the region of Idiobilayo, Foriku, Agbabu, Okitipupa, and Aiyibi [11,
12]. The resource base of Nigeria bitumen is enormous and can make a major contribution to oil and energy supply if it can be extracted and transformed into useable refinery raw material at costs that are competitive with alternative, hence making its delineation an important concern.

Though bitumen occurs in different part of the world but this research work shall be limited to the one in Agbabu, Southwestern, Nigeria.

Bitumen over Agbabu bitumen deposit appears to be a free flowing liquid at ambient temperatures and occurs at near surface (Figures 1 and 2). It is also adjudged to be the purest of all bitumen deposits in the world due to its extremely low sulphur content [13].

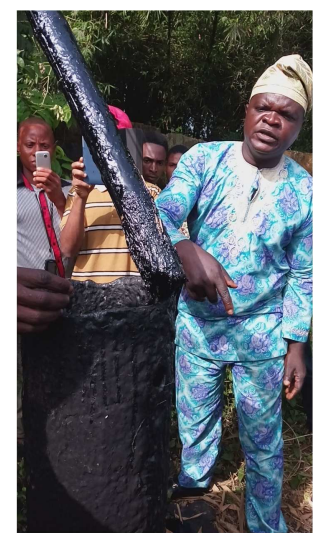

Figure 1. A chief showing natural (liquid form) bitumen at shallow depth in Agbabu.

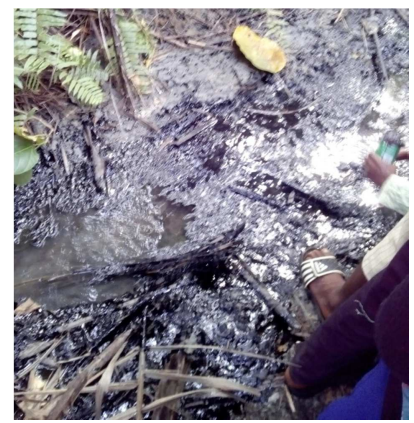

Figure 2. Showing natural (liquid form) bitumen flowing at surface at mile 2, Agbabu.

Several investigations have documented the use of electrical methods in characterizing of oil sands deposits. The application of this method is based on the fact that it is expected that the effect of bitumen saturation on the conductivity of various types of rocks should be negative i. e. increased resistivity and pronounced IP effects [14, 15].

In Nigeria, various authors have employed electrical methods in the exploration of heavy oil [2, 8, 12]. Also magnetic method has equally been used [16].

Therefore from various reviewed related studies in the area, the presence of bitumen is confirmed and there are no arguments or doubts about it. But this bitumen product has started affecting almost everything in Agbabu community (the study area) including their water, farm products and many other observed things that are likely to constitute 
environmental hazards. So there is the need to delineate the bitumen saturated zones within Agbabu in order to be able to map areas prone to pollution from bitumen effects now and in the future.

Hence, this research work utilizes integrated geophysical techniques involving electrical resistivity and groundmagnetic methods in the delineation of bitumen saturated zones in Agbabu. Ground magnetic method has been widely used for mapping Lithologic contact, delineation of faults, fractures, shear zones and joints etc. $(17,18,19)$, which are all necessary features in the accumulation of any mineral (bitumen inclusive).

\section{Location, Climate and Geology of the Study Area}

The area of study is area (Agbabu) is located within the geographical grids of latitude $6^{\circ} 35^{\prime} 16.3$ ' $\mathrm{N}$ and $6^{\circ} 37^{\prime}$ 13.9' $\mathrm{N}$ and longitudes $4^{\circ} 49^{\prime} 29.0^{\prime \prime} \mathrm{E}$ and $4^{\circ} 50^{\prime}$ 20.7'E.
Agbabu is in Odigbo local government area of Ondo state, Nigeria (Figure 3).

It falls within the sedimentary terrain in the Dahomey basin of southwestern, Nigeria [2, 8, 12].

The climate of Ondo State generally is of the low land tropical rain forest type with distinct wet and dry seasons from March to November. In the wet season, the temperature ranges from $21.3^{\circ} \mathrm{C}$ to $25.6^{\circ} \mathrm{C}$. Also, in the dry season the temperature ranges from $25.6^{\circ} \mathrm{C}$ to $31.3^{\circ} \mathrm{C}$. The relative humidity is relatively high (75\%) and annual rainfall of about $2000 \mathrm{~mm}$. It belongs to the high forest zone of rain forest, although the shifting cultivation system of the people has turned the high forest into shrubs and herb zone. The most important aspect of the vegetation of this southern region is the prevalence of tree crops $(10,20)$. The major tree crops include rubber and palm tree.

The drainage pattern observed in the study area is dendritic. They are characterized by irregular branching of tributary streams in many directions at almost any angles [2, 8, 12].

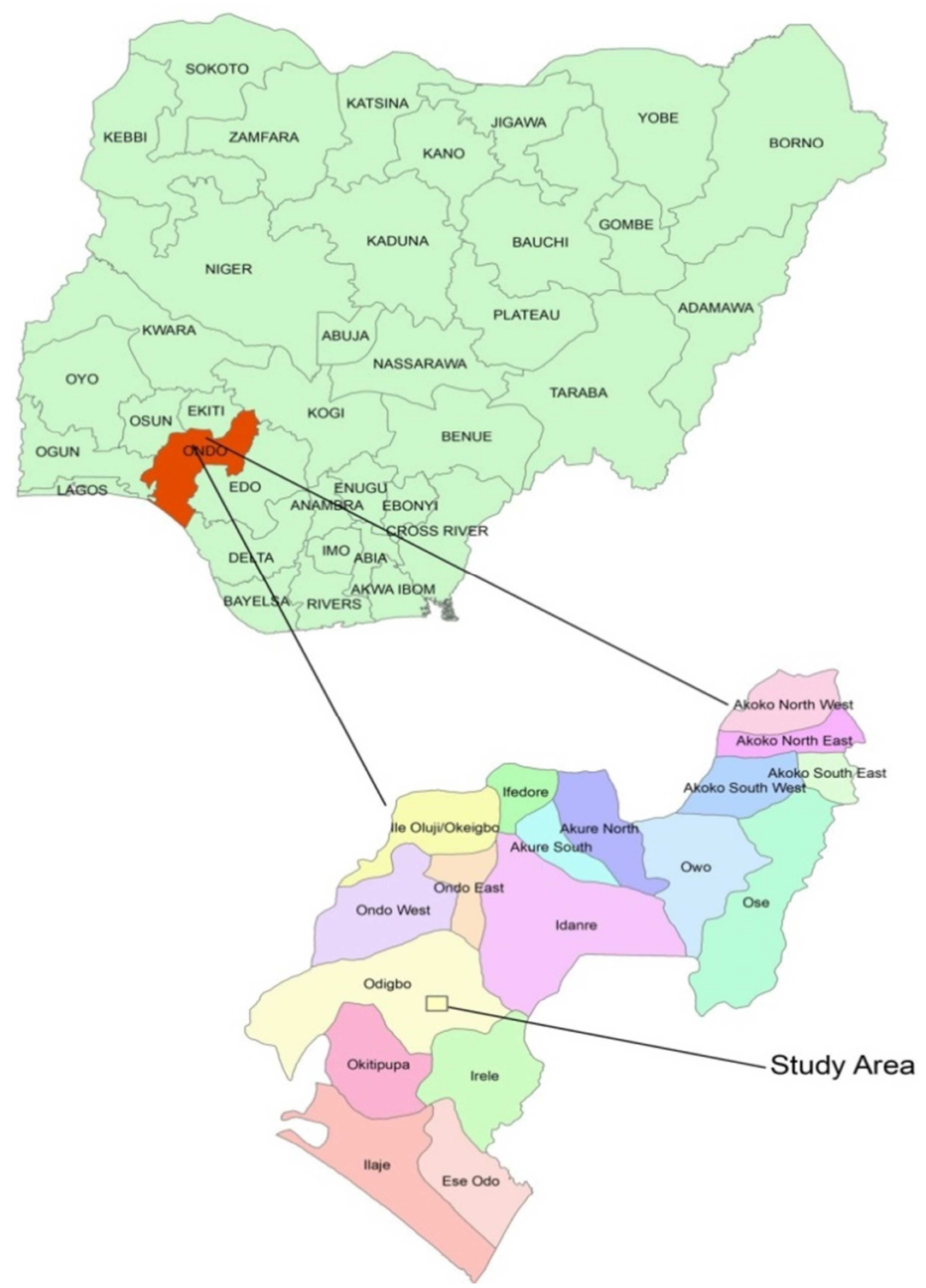

Figure 3. Map of Nigeria showing Ondo state and the study area. 


\section{Materials and Methodology}

Two methods of geophysical investigation were used in this research work. The groundmagnetic method and electrical resistivity method.

\subsection{Magnetic Method}

Investigating the bituminous zone using groundmagnetic method was adopted in mapping the subsurface geology of the study area with a view of having detailed information about the subsurface structural framework of the area $(17$, 18, 19). This will assist in subsequent planning for groundwater development, engineering works and environmental studies. The objective of this is to evaluate the linear geologic structures and its potential for bitumen accumulation. Magnetic method provides a relatively rapid and cost-effective means of deriving large area information coverage of subsurface geology. The magnetic field data was acquired by establishing four traverses along East - West direction of Agbabu cutting across some significant locations in the study area (Agbabu community), with the traverses each covering a total length of $120 \mathrm{~m}$ (figures 3 to 6). The principle of operation of magnetic method is based on the source of electromagnetic induction when a magnetic material is placed within the earth's magnetic field it develops an induced magnetic field. The field is superimposed on the earth's field at the point of creation of magnetic anomaly. The intensity of magnetization, I, is related to the strength of the inducing magnetic field, $\mathrm{H}$, through a constant of proportionality, k, known as magnetic susceptibility, and is given by,

$$
\mathrm{I}=\mathrm{kH} \text {. }
$$

The magnetic susceptibility is a unit-less constant that is determined by the physical properties of the magnetic material. It can take on either positive or negative values. Positive values imply that the induced magnetic field $\mathrm{I}$, is in the same direction as the inducing field, $H$. Negative values imply that the induced magnetic field is in the opposite direction as the inducing field. The basic field equipment used the groundmagnetic survey was the Proton precession magnetometer.

The groundmagnetic data was processed using excel software to generate 1-D curves (figures 3 to 6) to study the subsurface distribution of magnetic and non-magnetic materials along the traverses. A 2-D subsurface model (figures 7 and 8) using Oasis montaj (a computer software) was also generated to further study the subsurface distribution of the magnetic materials. Bitumen is ordinarily expected to be non-magnetic, so any zone or area with low magnetic signature are suspected to be bituminous zone, hence the usefulness of magnetic method.

\subsection{Electrical Resistivity Method}

Under the electrical resistivity method, two techniques were employed, the horizontal electrical profiling (HEP) and the vertical electrical sounding (VES).

For the horizontal electrical profiling, the Wenner electrode configuration was used during the resistivity measurements with electrode spacing of $5 \mathrm{~m}$ and a maximum spread of between $95 \mathrm{~m}$ and $125 \mathrm{~m}$ spread established in the North-South direction.

The data were processed by using excel computer package, to generate 1-D resistivity curves (figures 11 to 14 ) in order to study the distribution of subsurface electrical materials in terms of their conductivity or resistivity along the established traverse lines. The resistivity of bituminous zones is expected to be high, but the reverse is the case in Agbabu community. This is probably due to the intrusion of the saline water from coast, for the community is banded by the coastal water in the eastern part of the community (figure 3). So the anomalously conductive or low resistive zones were marked and further probed using vertical electrical sounding (VES), this is to properly study the layer parameters in terms of their resistivity/conductivity, thickness and depth to the anomalous zones.

The basic equipment for the electrical resistivity method is the resistivity meter, which displays apparent resistivity values digitally as computed from Ohm's law,

$$
\mathrm{V}=\mathrm{IR}
$$

From the current (I) and voltage (V) values, an apparent resistivity $(p a)$ value is calculated.

$$
\rho_{\alpha}=K V / I
$$

Where $\mathrm{k}$ is the geometric factor which depends on the arrangement of the four electrodes.

Other accessories to the Resistivity meter include the four metal electrodes, cables for current and potential electrodes, harmers (four), measuring tapes, writing pads.

For the HEP, using Wenner electrode configuration, the apparent resistivity of the subsurface was computed using the following formular;

$$
\rho=2 \pi \mathrm{aR}
$$

where $\mathrm{a}=$ electrode spacing and $\mathrm{R}=$ resistance. And for the VES, using Schlumberger electrode array, the apparent resistivity of the subsurface was also computed using the following mathematical expression,

$$
\rho=\frac{\pi L^{2}}{2 l}\left(\frac{\Delta V}{I}\right),
$$

The apparent resistivity values obtained were plotted against the current electrode separation for each VES point to obtain the resistivity curve types reflective of the subsurface geology for the area.

The calculated resistivity value is not the true resistivity of the subsurface, but an "apparent" value which is the resistivity of a homogeneous ground which will give the 
same resistance value for the same electrode arrangement. The relationship between the "apparent" resistivity and the "true" resistivity is a complex relationship, so to determine the true subsurface resistivity, an inversion of the measured apparent resistivity values using a computer program must be carried out.

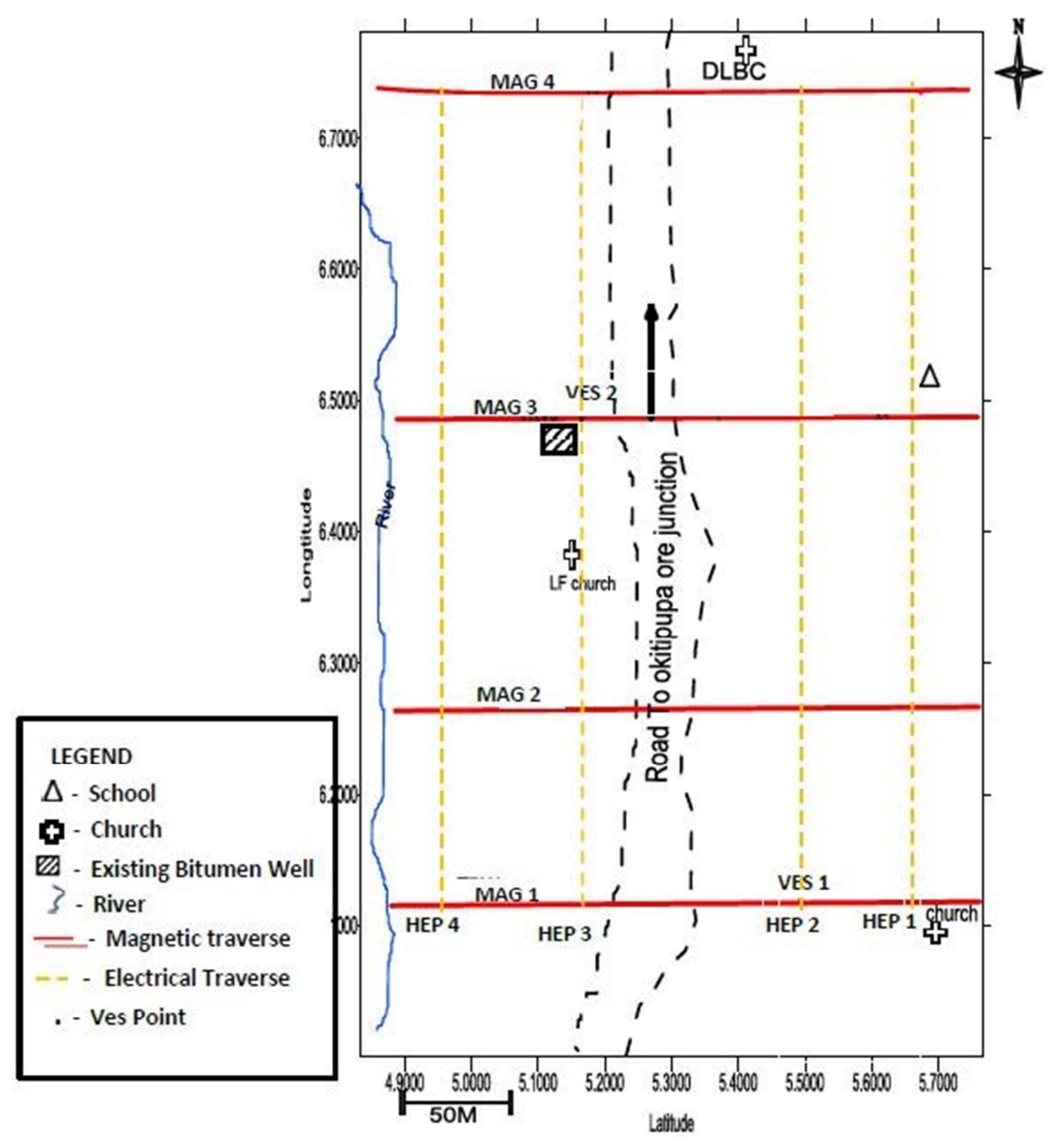

Figure 4. Base Map of the Study Area showing the VES points, magnetic and HEP traverses.

\section{Results and Discussion}

\subsection{Groundmagnetic}

The purpose of magnetic survey is to locate rocks or mineral having unusual magnetic properties which revealed themselves as anomalies in the intensity of the earth's magnetic field [18, 19, 21].

One of the major uses of shape (s) of magnetic anomaly curves is in the qualitative estimate of area of extent of the anomaly and the depth estimate of the anomaly [22]. When a profile curve has a broad shape, it is an indicative of an anomaly of a wide or large area of extent and deeply buried but when it is sharp, it is an indicative of a shallow buried anomaly.

A total of four magnetic profiles each covering a spread of $120 \mathrm{~m}$ along the traverse lines were established and presented as $1 \mathrm{D}$ profiling curves (Figures 5 to 8 ) and 2-D imaging form (Figures 7 and 8) to qualitatively study the subsurface geologic structure within the study area. From the obtained magnetic readings, a plot the magnetic values against distance was made, using Microsoft Excel computer software package for the $1 \mathrm{D}$ profiling curves, and Oasis Montaj for the $2 \mathrm{D}$ curves.

The profile curves on the four traverses showed the study area to be generally composed of non-magnetic anomalies even aside the area being a sedimentary environment. The negative peaks depict areas of abnormally low magnetic anomalies zones. The broad shapes of negative peaks along traverses 1 and 2 are indicative of wide area of extent of nonmagnetic anomalous body that is a bit deeply buried at the subsurface. Traverse 3 which is located along the direction of an existing bitumen well (Figure 1) showed a very sharp negative peak (at $70 \mathrm{~m}$ away from station 0 ) indicating an anomaly (bitumen) of a very shallow depth. Traverse 4 also showed the continuation of the shallow anomalous body of traverse 3 . Since the purpose of using magnetic method for this research work is to look for areas of abnormally low magnetic responses or signatures and suspect the area as bituminous zone, so from findings so far, presence of bitumen even at shallow depth is suspected. 


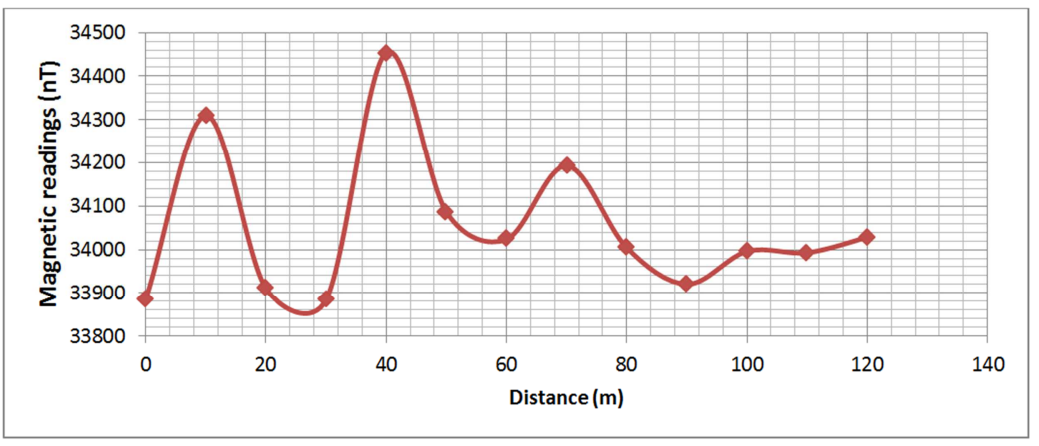

Figure 5. Magnetic profile 1 along East-West direction.

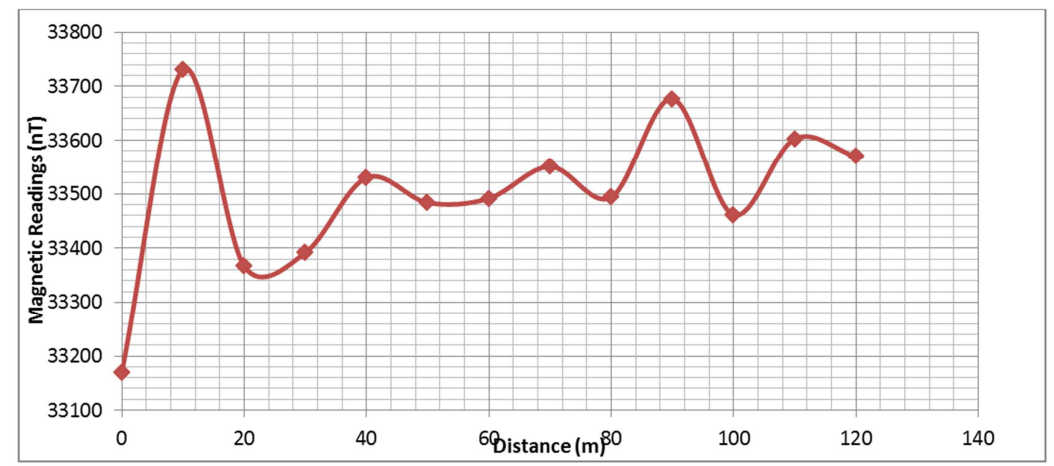

Figure 6. Magnetic profile 2 along East - West direction.

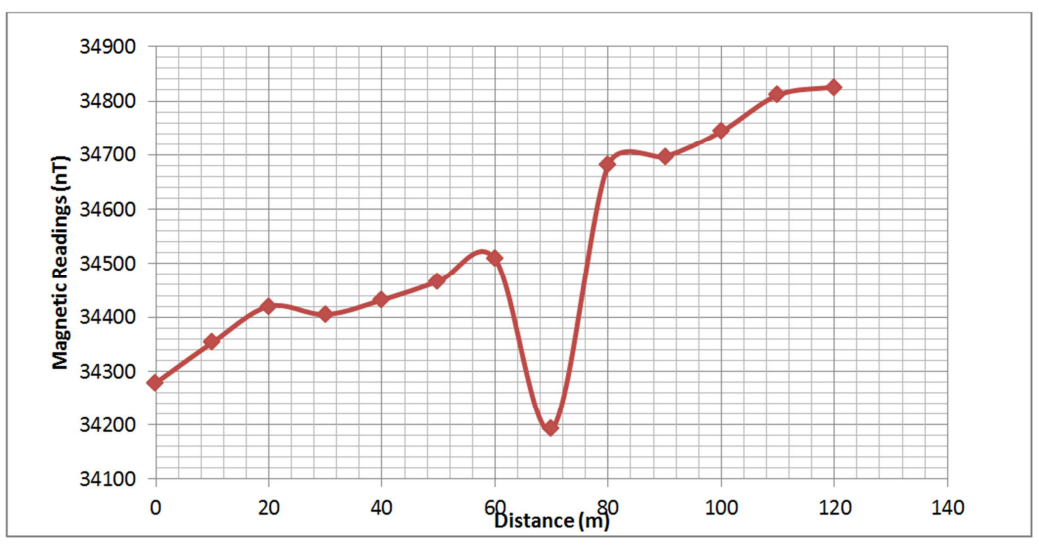

Figure 7. Magnetic profile 3 along East - West direction.

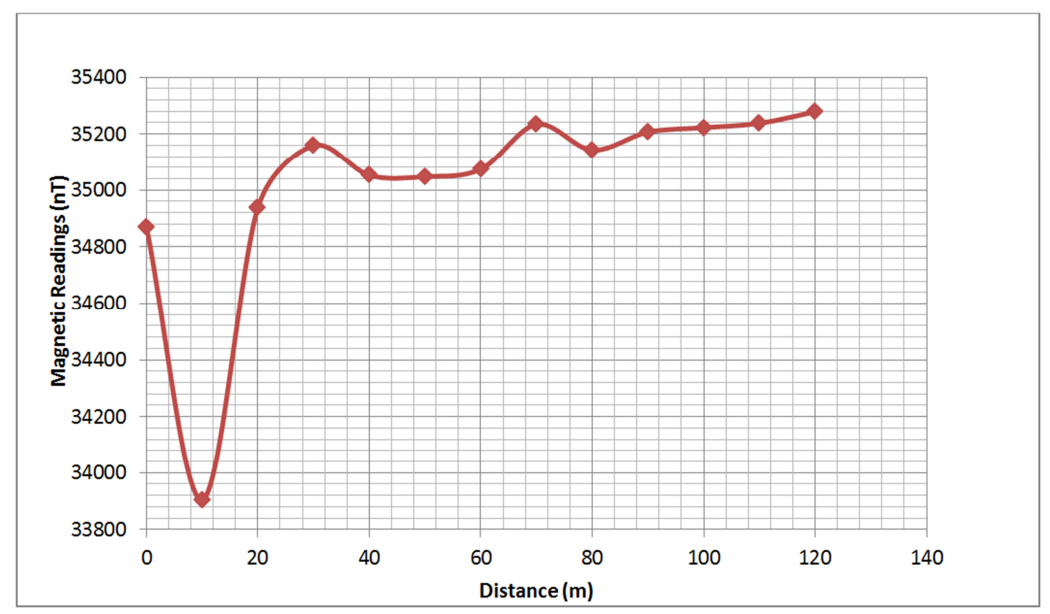

Figure 8. Magnetic profile 4 along East - West direction. 
The total magnetic intensity (TMI) map of the study area is depicted in 2D form (Figure 9). The subsurface is composed of four magnetic/geologic layers, the topsoil which is the first layer (pink colour coded) is sand, the second layer (red colour coded) is clayey sand, the third layer is the bituminous zone (green colour coded) while the fourth layer (blue colour coded) is assumed to be the ocean depth, composed of saline water. The third layer (zone of interest), which is the bituminous zone trend from east to west (Figure 9) with magnetic intensity values ranging between $34104.2 \mathrm{nT}$ to $34423.5 \mathrm{nT}$. The thin yellow band between second layer and the third layer is the clay protective cap shielding the bitumen from escaping to the surface, thereby serving as a cap protecting the surface water and the shallow hand-dug wells.

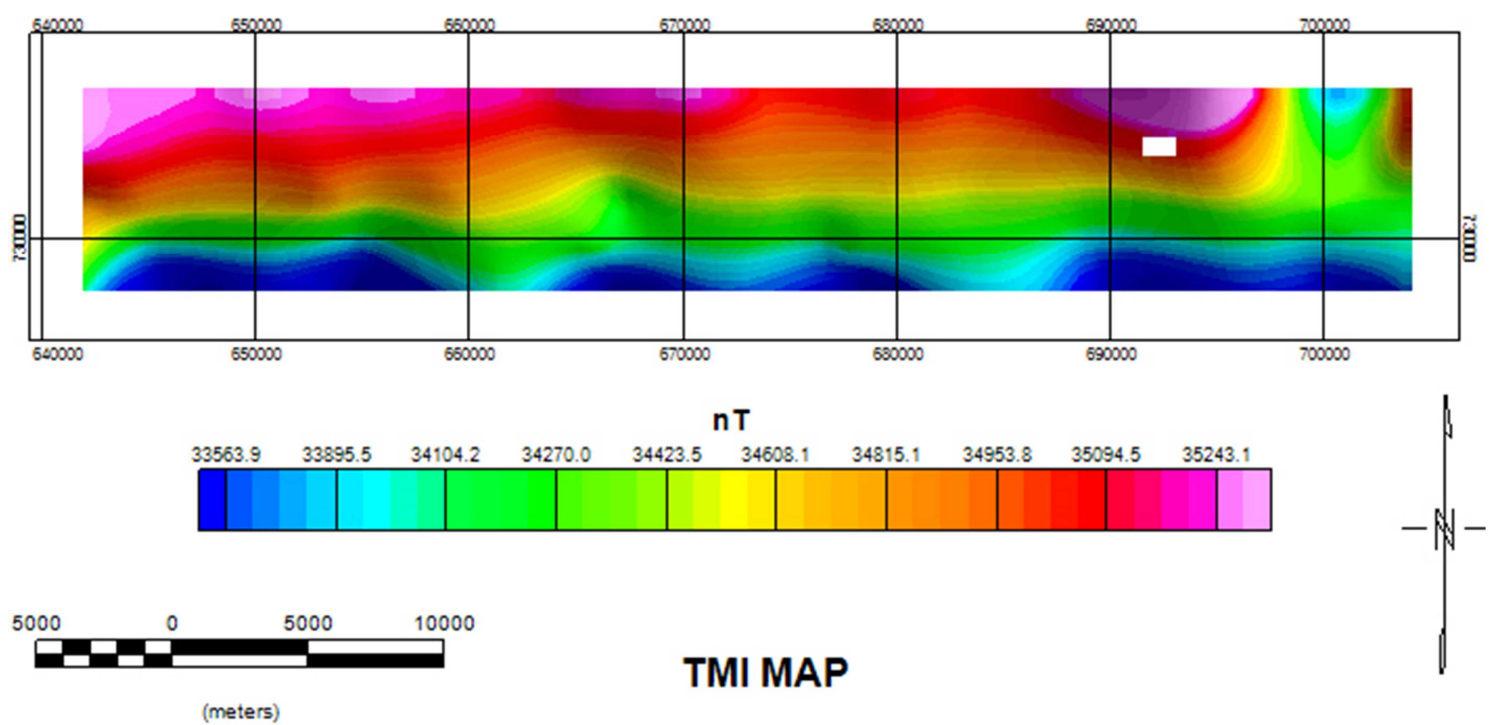

Figure 9. Total magnetic intensity map of the study area.

The features in the TMI map appears to be regional so a residual map was generated to reveal more local effects from the study area (Figure 10). The residual map revealed some weak zones through which the bitumen (green colour coded) was suspected to have been able to escape or migrated to the surface and the existing together of the saline water (blue colour coded), and the bitumen in some cases. This proves the near-surface and surface occurrence of natural or liquid bitumen at Agbabu and Mile 2 respectively.

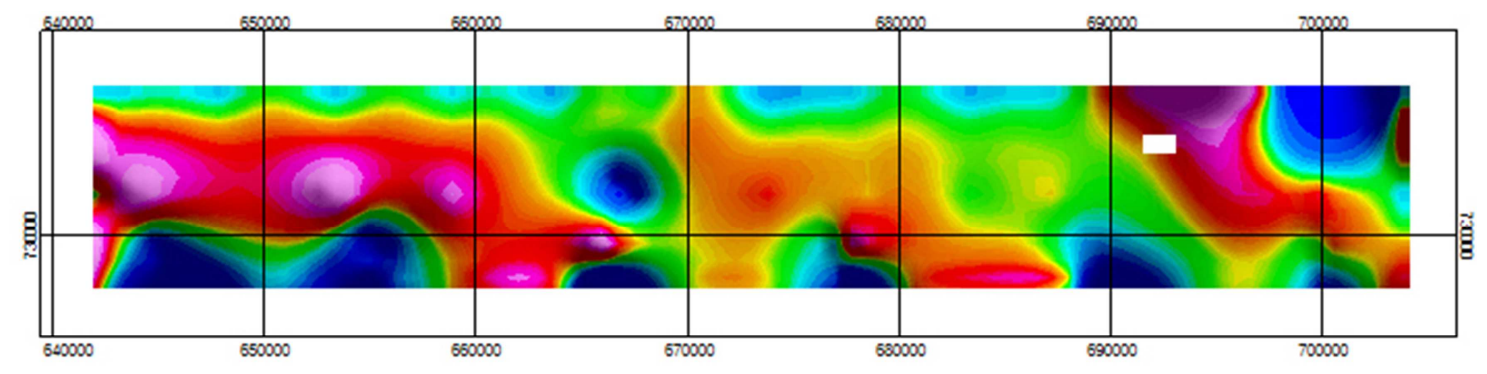

$\mathrm{nT}$
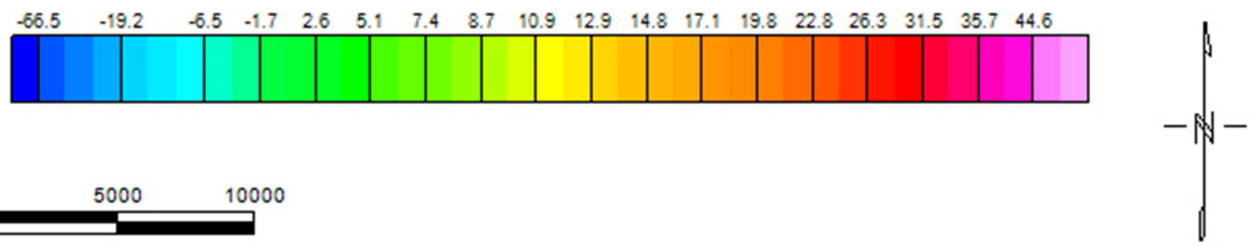

(meters)

\section{RESIDUAL MAP}

Figure 10. Residual magnetic map of the study area.

\subsection{Electrical Resistivity Method}

\subsubsection{Horizontal Electrical Profiling (HEP)}

Four electrical resistivity profiles were established in the
North-South direction for the horizontal electrical profiling (HEP) (Figure 3). The apparent resistivity values were plotted against distance in metres. The resistivity values were generally low across the study area it ranges between $20 \Omega \mathrm{m}$ 
to $180 \Omega \mathrm{m}$. This resistivity lows is suspected to be as a result of the intrusion of saline water from the ocean to the bituminous zones in the study area (Figure 10). The HEP was majorly used to study the electrical variation in the lateral extent of the suspected bituminous zones. A close observation of the four profiles (figures 11 to 14) showed an increase in the resistivity values towards the western flank of the study area on traverses 1 and 2 (Figures 11 and 12) while it decreases towards the same western flank of the study area on traverses 3 and 4 (Figures 13 and 14). This is probably as a result of the degree of lateral extent of bitumen to the western portion of the area (i.e. towards Mile 2).

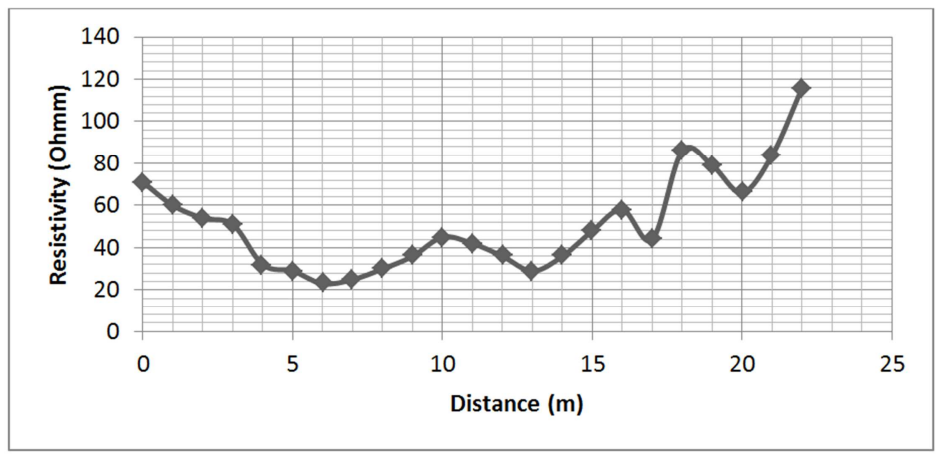

Figure 11. Horizontal Electrical Profile along traverse 1.

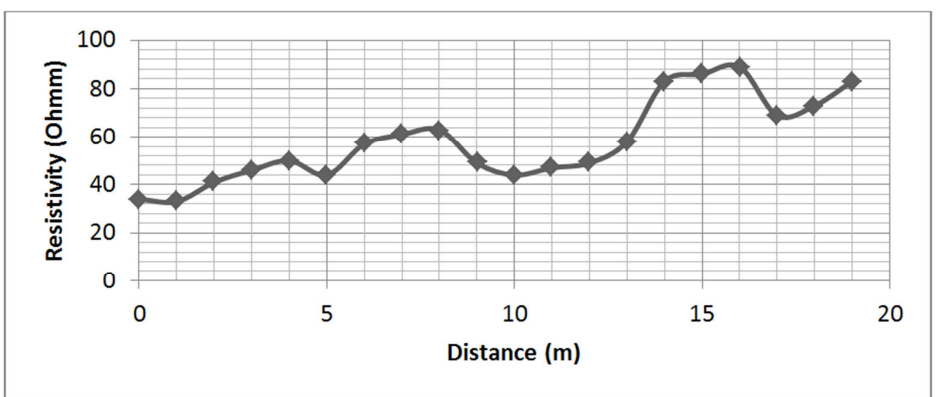

Figure 12. Horizontal Electrical Profile along traverse 2.

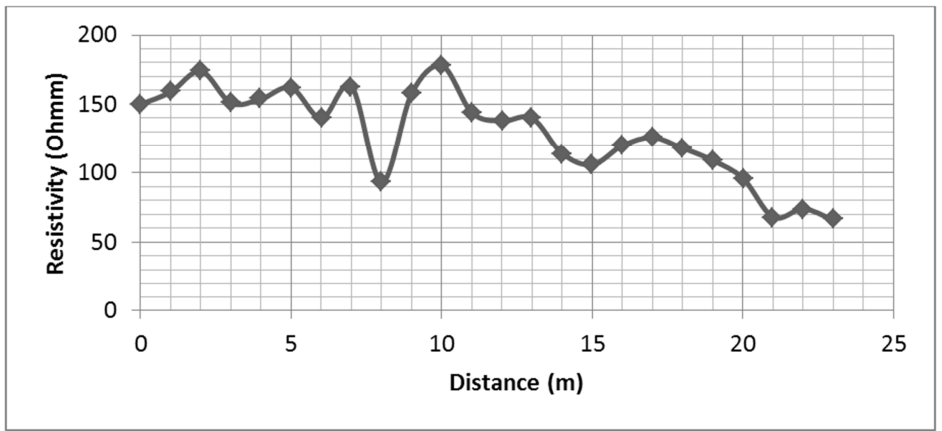

Figure 13. Horizontal Electrical Profile along traverse 3.

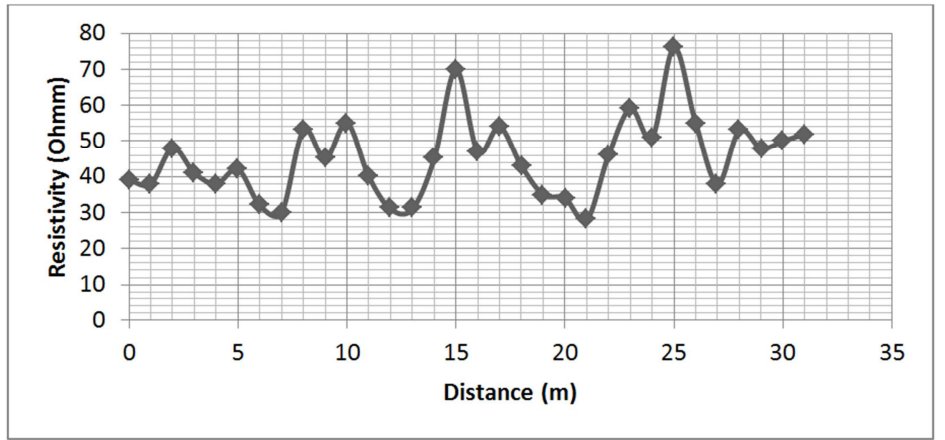

Figure 14. Horizontal Electrical Profile along traverse 4. 


\subsubsection{Vertical Electrical Sounding}

Based on the trend and the result of the HEP, a low resistivity point was randomly selected on each of the profiles 1 and 3 which assumed to be a representative of the two trends in the study area and was further probed using vertical electrical sounding (VES). The VES is done to study the layer parameters such as the layer's resistivity, thickness and depth to the bituminous zones. VES1 was carried out on HEP traverse 1 and VES2 on HEP traverse 3.

VES1 (figure 15) is a typical curve showing five geologic layers. First layer which is the topsoil is composed of laterite/ clayey with a resistivity value of $769.0 \Omega \mathrm{m}$ occurring at a depth of $0.8 \mathrm{~m}$. Second layer is the clay-cap on the bitumen with resistivity value of $74.2 \Omega \mathrm{m}$ at a depth of $3.1 \mathrm{~m}$. The third layer is the bituminous zone occurring at a depth between $3.1 \mathrm{~m}$ and $7.7 \mathrm{~m}$ and has a resistivity value of 276.0
$\Omega \mathrm{m}$. The bituminous zone is underlain by saline water zone in the fourth layer with resistivity value of $4.5 \Omega \mathrm{m}$, while the fifth layer is the assumed unresolved basement.

VES2 (figure 16) is also a curve with six geologic layers. The first layer with a resistivity value of $451.4 \Omega \mathrm{m}$ at a depth of $0.7 \mathrm{~m}$ is interpreted as the topsoil made up of laterite/clayey. The second layer here is also interpreted to be a clay-cap on the bitumen and has a resistivity value of 194.0 $\Omega \mathrm{m}$ at a depth of $2.3 \mathrm{~m}$. The third layer is the bituminous saturated zone at the depth of $5.0 \mathrm{~m}$ and with resistivity value of $508.9 \Omega \mathrm{m}$, occurring at depth of $5.0 \mathrm{~m}$. The fourth layer is an extension of the third layer but more diluted with saline water and has a resistivity value of $197.4 \Omega \mathrm{m}$ occurring at a depth of $23.3 \mathrm{~m}$. This fourth layer is also underlain by saline water zone with resistivity value of $9.3 \Omega \mathrm{m}$ at a depth of $84.2 \mathrm{~m}$. The sixth layer is the assumed unresolved basement.

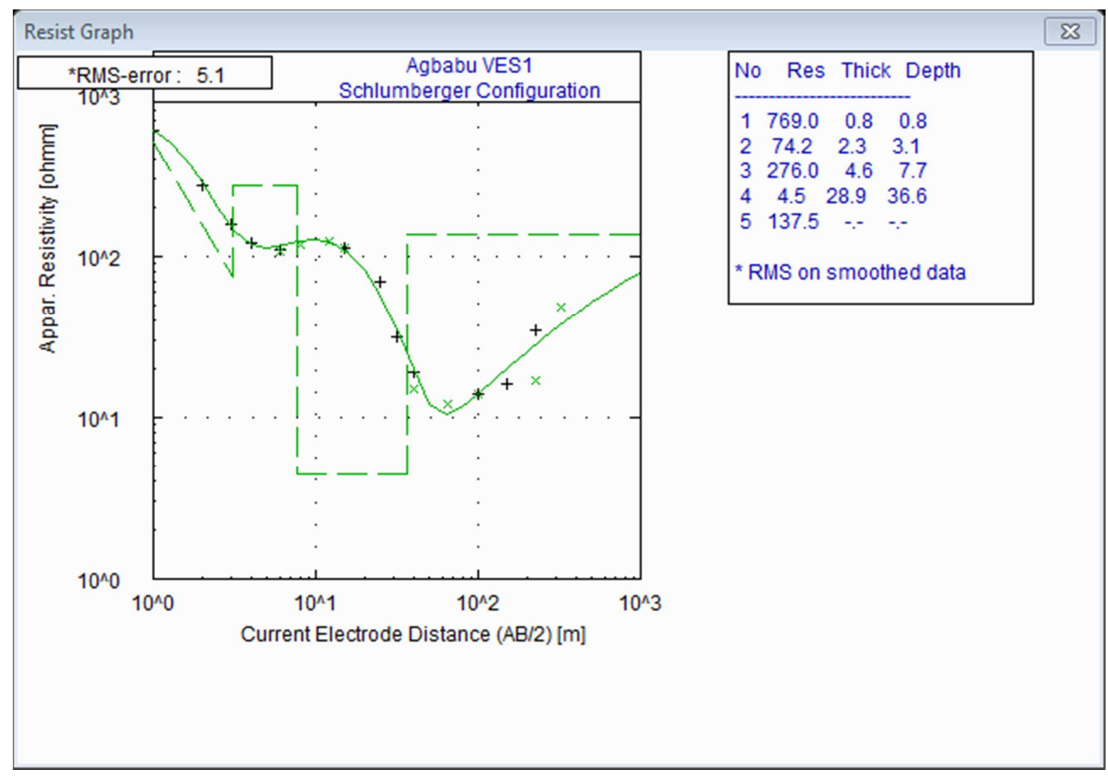

Figure 15. VES1 carried out on HEP traverse 1.

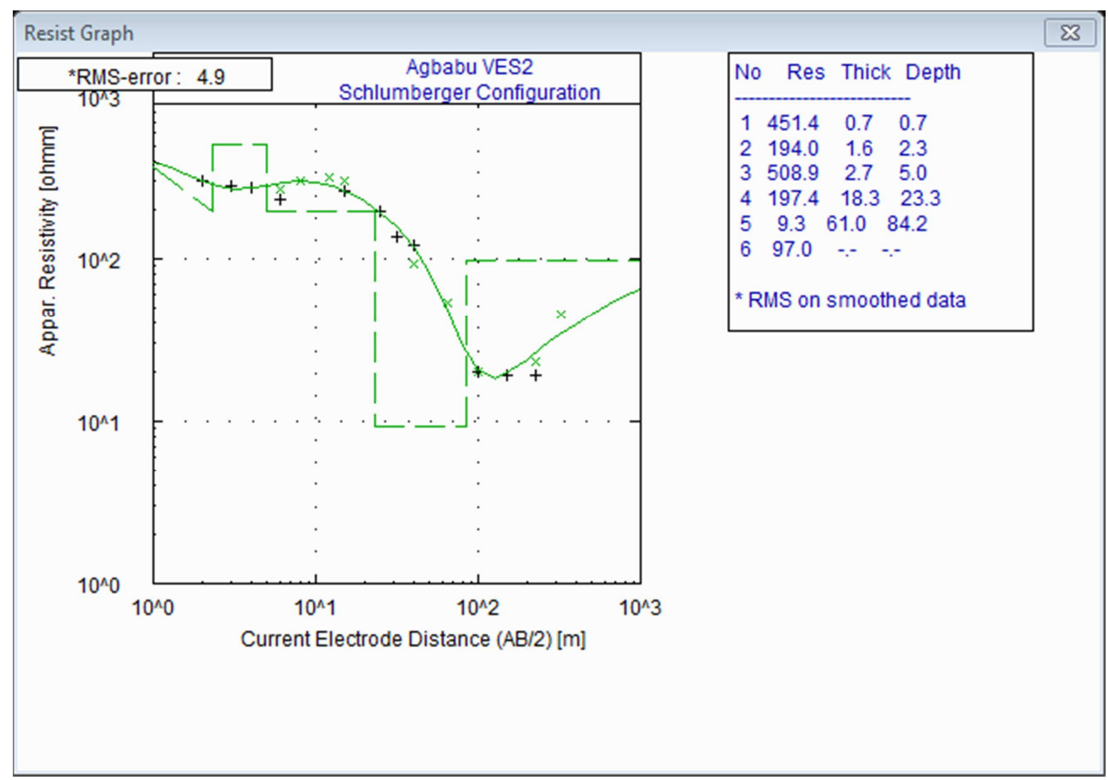

Figure 16. VES2 carried out on HEP traverse 3. 


\section{Conclusion}

Two major geophysical methods (Magnetic and Electrical Resistivity methods) have been applied in an attempt to delineation of bitumen saturated zones in Agbabu. The magnetic method showed features that could be interpreted as bitumen occurring at shallow depth. The method also revealed some geologic features such as fractures, contacts and others that could be described as weak zones within the study area which has probably assisted the migration of the bitumen to the near-surface by serving as pathway. Two techniques was adopted under electrical resistivity method to both qualitatively and quantitatively explore the subsurface information.

The horizontal electrical profiling was used for the qualitative analysis and it generally revealed low resistivity across the study area. The low resistivity has been attributed to the study area been close to the coast and as a result of saline water intrusion. The vertical electrical sounding was used for quantitative analysis. The two VES curves generated showed between five and six geologic layers in the area studied and also showed the bitumen saturated zones to be within the third and fourth layers with the depth range of $5.0 \mathrm{~m}$ to $7.7 \mathrm{~m}$ downwards respectively and it is underlained by saline water. Generally, it could be concluded that the low resistivity values over Agbabu bituminous zones is as a result of intrusion saline water into the near-surface bituminous zones.

\section{References}

[1] Attanasi, E. D and Meyer, R. F. (2007): Natural bitumen and extral-heavy oil, in 2007. Survey of Energy Resources, eds., J. Trinnaman and a. Clarke: World Energy Council, pp 119-143.

[2] Ako BD, Alabi AO, Adekoe OS, Enu EI (1983). Application of Resistivity Sounding in the Exploration for Nigeria Tar Sand, Energy and Exploitation (C) Graham and Trotman Limited 2 (2): 155-164.

[3] Omatsola ME, Adegoke OS (1981). Tectonic evolution and Cretaceous Stratigraphy of Dahomey Basin Nigeria. J. Min. Geol. 1: 44-48.

[4] Kingston D. R., Dishroon C. P. and Williams P. A., (1983): Global Basin Classification System, AAPG. Bull., Vol. 67, pp. 2175-2193.

[5] Asubiojo, O. I. and Adebiyi, F. M. (2013): The Impact of Bitumen Deposits on Groundwater Quality. Journal, Energy Sources, Part A: Recovery, Utilization, and Environmental Effects, Vol. 36, issue 4, Pp 445-456.

[6] Adegoke OS, Enu EI, Ajayi TR, Ako BD, Omatsola ME, Afonja AA (1981). Tar Sand a New Energy Raw Mater. in Nigeria Proceeding Symposium on New Energy Raw Material. karlovy, pages pp. 17-22.

[7] Enu, E. I. (1985): Textural characteristic of the Nigeria Tar sands. Sedimentology geology. Vol. 44, pp 65-81.

[8] Odunaike RK, Laoye JA, Fasunwon OO, Ijeoma GC,
Akinyemi LP (2010). Geophysical mapping of the occurence of shallow oil sands in Idiopopo at Okitipupa area, Southwestern, Nigeria. Afr. J. Environ. Sci. Technol. Vol. 4 (1) pp. 034-044.

[9] Odunaike R. K., Ijeoma G. C., Edigbe R. O., Babatope A. H., (2009): Oil Sands Exploration in Ijebu-Imushin Using Magnetic and Electrical Resistivity Method: 11th SAGA Biennial Meeting and Exhibition Swaziland, 247- 252.

[10] Alagbe, O. A. (2018): 2D Geoelectrical Resistivity Imaging for the Assessment of Subsurface Soil Corrosivity Zones at a Proposed Filling Station Site in Akure, Southwestern Nigeria. International Advance Research Journal in Science, Engineering and Technology, Vol. 5, Issue 11, Pp 58-73.

[11] Federal Ministry of Solid Minerals Development (FMSMD) (2006). Technical Overview in Nigeria's Bitumen Belt and Development Potential. Report, PP. 1-14, Federal Ministry of Solid Minerials Development, Abuja, Nigeria.

[12] Akinmosin A, Omosanya KO, Ariyo SO, Folorunsho AF, Aiyeola SO (2011). Structural control for Bitumen Seepages in Imeri, Southwestern, Nigeria. International Journal of Basic and Applied Sciences IJBAS-IJENS Vol: 11 No: 01, 93-103.

[13] Akinmosin, A.(2012). Characterization of a bitumen seepage in Eastern Dahomey Basin, SW, Nigeria. Advances in Applied Science Research, 3 (4): 2078-2089.

[14] McConnel, D. and Glen, T. (2008): Athabasca oil sands exploration and development investigation using the helicopter-borne transient electromagnetic techni, Back to exploration-2008 CSPG CWLS convention pp 701-705.

[15] Bauman, P. (2005): 2-D Resistivity Surveying for hydrocarbon-A Primer. CSEG Recorder, April, pp 25-33.

[16] Okpoli, C. K. and Eyitoyo, F. B (2016): Aeromagnetic Study of Okitipupa Region, Southwestern Nigeria. International Basic and Applied Research Journal, Vol. 2, No. 7 PP 1-20.

[17] Sunmonu, L. A.; Alagbe, O. A. and Adeniji, A. A. (2014): Groundmagnetic method for subsurface structural analysis around Ogbagba, Southwestern Nigeria. Open Transactions on Geosciences, vol. 1, No. 4, Pp 1-10.

[18] Sunmonu, L. A. and Alagbe, O. A. (2011): Groundmagnetic study to locate buried faults (A case study of abandoned local governmemt secretariat in Ogbomoso). International Journal of Physics, vol. 3, No. 1, Pp 70-75.

[19] Alagbe, O. A; Sunmonu, L. A; Adabanija, M. A (2010), Study on the groundwater accumulation Oke-Ogba area using ground magnetic survey. J. Appl. Sci. Environ. Manage. December, Vol. 14 (4) 25-30.

[20] Alagbe, O. A.; Sanusi, S. O. and Bamigboye, A. A. (2019): 2D Electrical resistivity Prospecting for Groundwater at the Premises of the Staff Quarters of Elizade University, Ilara Mokin, Ondo State, Nigeria. World Journal of Innovative Research, Vol. 6, issue 2, Pp 100-108.

[21] Sunmonu, L. A. and Alagbe, O. A. (2014): Interpretation of Aeromagnetic Data of Kam, Using Semi- Automated Techniques. International Research Journal of Earth Sciences, Vol. 2 (2) PP 1-18.

[22] Alagbe, O. A. (2015): Depth Estimation From Aeromagnetic Data of Kam. International Journal of Advanced Research in Physical Science, vol. 2, issue 1, Pp 1-5. 